\title{
Vasopressin Receptor Antagonists (Vaptans) in Heart Failure
}

\section{Piotr Lipiec ${ }^{1}$, Marco Metra ${ }^{2}$}

1. Department of Cardiology, Medical University of Lodz, Poland

2. Professor of Cardiology, Department of Medical and Surgical Specialties, Radiological Sciences, and Public Health, University of Brescia, Spedali Civili, Brescia Italy

\section{Corresponding author:}

Piotr Lipiec, Head of the Department of Rapid Cardiac Diagnostics

Medical University of Lodz, UI. Kniaziewicza 1/5, 91-347 Lodz, Poland.

Email: lipiec@ptkardio.pl

\begin{abstract}
Vasopressin receptor blockade is an interesting therapeutic target in patients with heart failure. To date, however, clinical trials of vasopressin antagonists have failed to demonstrate any significant benefits in term of long-term mortality or heart failure-related morbidity. Limited short-term beneficial clinical effects reported in patients with acute heart failure, volume overload and resistant hyponatraemia translate into only a limited role of vaptans in recommended management of this patient population.
\end{abstract}

Keywords: heart failure; hyponatraemia; tolvaptan, vasopressin antagonists, vaptans

Citation: $\quad$ Lipiec P and Metra M. Vasopressin Receptor Antagonists (Vaptans) in Heart Failure. International Cardiovascular Forum Journal. 2019;17:37-38. DOI: 10.17987/icfj.v17i0.605

\begin{abstract}
Introduction
Hyponatraemia is a relatively prevalent laboratory finding in $\mathrm{HF}$ - it has been observed in almost one in every five patients hospitalized with new-onset or worsening HF.[1] Importantly, in this population hyponatraemia has been shown to be associated with longer hospital stays as well as higher inhospital and long-term mortality.[2] Arginine vasopressin is a peptide neuroendocrine hormone, increased levels of which are found in patients with HF.[3] Acting through 3 subtypes of receptors, it causes vasoconstriction and cardiac remodeling (receptors $V_{12}$ ), adrenocorticotropic hormone release (receptors $\mathrm{V}_{1 \mathrm{~b}}$ ) and water reabsorption (receptors $\mathrm{V}_{2}$ ), thus increasing preload and afterload.
\end{abstract}

Differences between vasopressin-receptor antagonists Vasopressin-receptor antagonists (vaptans), which induce hypotonic diuresis and are aimed at the treatment of hyponatraemia, have been proposed as a therapeutic option for patients with HF.[4] Three of these agents have been more extensively studied in this clinical scenario, namely: tolvaptan, conivaptan and lixivaptan (table 1). However, only tolvaptan and conivaptan have been approved for clinical use in hyponatraemia (in the USA). Lixivaptan, following the FDA's rejection of approval for treatment of hyponatraemia, is now repurposed and being developed for the treatment of autosomal dominant polycystic kidney disease.

\section{Evidence from clinical trials}

The largest study on the use of tolvaptan in HF patients was the EVEREST trial (Efficacy of Vasopressin Antagonism in Heart Failure Outcome Study With Tolvaptan). The authors of this prospective, multicentre, randomized, double-blind, placebocontrolled study assessed the short- and long-term efficacy and safety of tolvaptan added to optimal treatment in over 4100 patients hospitalized with an exacerbation of chronic HF with reduced LVEF. They observed no effect on long-term mortality or HF-related morbidity[6], but during short-term follow-up there was a greater weight loss accompanied by an attenuation in many signs and symptoms of HF, including dyspnoea and oedema. Importantly, there was no excess of serious adverse events, including renal failure and hypotension in an active treatment arm.[7] Similar observations regarding the short-term efficacy of adding tolvaptan for relieving dyspnoea have also been demonstrated in acute HF patients with diminished renal function in the AQUAMARINE study (Answering the Question of Tolvaptan's Efficacy for Patients With Acute Decompensated Heart Failure and Renal Failure). [8]

In contrast, the more recent, but much smaller (257 patients) TACTICS-HF trial (Targeting Acute Congestion with Tolvaptan in Congestive Heart Failure) - has shown that administration of tolvaptan in patients hospitalized due to acute HF and congestion resulted in an increased reduction in body weight and the greater net fluid loss, but with no difference in dyspnoea relief, 
Table 1. Characteristics of the most extensively studied vasopressin-receptor antagonists[5].

\begin{tabular}{|c|c|c|c|}
\hline & Conivaptan & Tolvaptan & Lixivaptan \\
\hline $\begin{array}{l}\text { Mechanism of } \\
\text { action }\end{array}$ & $\begin{array}{l}\text { non-selective } \\
\text { V1a and V2 } \\
\text { antagonist }\end{array}$ & $\begin{array}{l}\text { selective V2 } \\
\text { antagonist }\end{array}$ & $\begin{array}{l}\text { selective V2 } \\
\text { antagonist }\end{array}$ \\
\hline $\begin{array}{l}\text { Route of } \\
\text { administration }\end{array}$ & intravenous & oral & oral \\
\hline Dosing & $20-40 \mathrm{mg} / \mathrm{d}$ & $15-60 \mathrm{mg} / \mathrm{d}$ & $10-400 \mathrm{mg} / \mathrm{d}$ \\
\hline $\begin{array}{l}\text { Elimination } \\
\text { half-life }\end{array}$ & 3-8 hours & $6-8$ hours & $7-10$ hours \\
\hline
\end{tabular}

or in-hospital or post-discharge clinical outcomes.[9] Moreover, tolvaptan-treated patients were more likely to experience worsening renal function.

Importantly, tolvaptan has been shown to be effective in increasing serum sodium concentrations in patients with hyponatraemia, both in cases of acute and chronic HF.[10,11] The most common side effects associated with tolvaptan administration, described consistently in the literature, have included thirst, dry mouth and increased urination.

There are fewer data available on the use of conivaptan in patients with HF, compared to tolvaptan. In a study comprising 142 patients with symptomatic HF, the administration of conivaptan led to increased urine output and a decrease in pulmonary capillary wedge pressure and right atrial pressure, with no significant changes in blood pressure and heart rate.[12] This improvement in urine output without affecting vital signs has been confirmed in another later study.[13]

Vasopressin receptor antagonists have also been studied in the setting of decompensated right-sided HF. Vidic et al. in a retrospective observational study including patients hospitalized with clinical and echocardiographic evidence of right-sided HF have shown that the use of vaptans $(90 \%$ of patients received tolvaptan and the remaining $10 \%$ were treated with conivaptan) was associated with a significant increase in urine output and serum sodium with a decrease or stabilization of diuretic dosing in the early treatment period.[14] The authors concluded that vaptans may be useful in patients failing conventional diureticbased treatment, although being an observational study an effect of selection bias cannot be excluded.

\section{Vasopressin-receptor antagonists in the European Society of Cardiology guidelines on heart failure}

In the most recent 2016 European HF guidelines, vaptans receive relatively little discussion, and only a limited recommendation for patients with HF, with the statement that "Tolvaptan may be used to treat patients with volume overload and resistant hyponatraemia" based on the EVEREST trial.[15]

\section{Conclusions}

Due to a relatively high prevalence of hyponatraemia in $\mathrm{HF}$ patients and the role of vasopressin in this electrolyte and volaemia abnormality, as well as the influence of hyponatraemia and increased levels of vasopressin itself on worse clinical outcomes in this population, the vasopressin receptors blockade seems to be an appealing therapeutic target. However, currently available data suggest no influence of vasopressin receptor antagonists (vaptans) on long-term mortality or HF-related morbidity. Limited short-term beneficial clinical effects described in patients with acute HF with volume overload and resistant hyponatraemia mean that this interesting class of agents play only a minor role in our management of the population burden of HF.

\section{Declarations of interest}

The authors declare no conflict of interest.

\section{Acknowledgements}

The authors state that they abide by the authors' responsibilities and ethical publishing guidelines of the International Cardiovascular Forum Journal.[16]

\section{References}

1. Gheorghiade M, Abraham WT, Albert NM, et al. Relationship between admission serum sodium concentration and clinical outcomes in patients hospitalized for heart failure: an analysis from the OPTIMIZE-HF registry. Eur Heart J. 2007;28(8):980-8.

2. Bettari L, Fiuzat M, Shaw LK. Hyponatremia and long-term outcomes in chronic heart failure--an observational study from the Duke Databank for Cardiovascular Diseases. J Card Fail. 2012;18(1):74-81.

3. Francis GS, Benedict C, Johnstone DE, et al. Comparison of neuroendocrine activation in patients with left ventricular dysfunction with and without congestive heart failure. A substudy of the Studies of Left Ventricular Dysfunction (SOLVD). Circulation. 1990;82(5):1724-9.

4. Vinod P, Krishnappa V, Chauvin AM et al. Cardiorenal Syndrome: Role of Arginine Vasopressin and Vaptans in Heart Failure. Cardiol Res. 2017;8(3):87-95.

5. Peri A. Clinical review: the use of vaptans in clinical endocrinology. J Clin Endocrinol Metab. 2013;98(4):1321-32

6. Konstam MA, Gheorghiade M, Burnett JC Jr, et al. Effects of oral tolvaptan in patients hospitalized for worsening heart failure: the EVEREST Outcome Trial. JAMA. 2007;297(12):1319-31

7. Gheorghiade M, Konstam MA, Burnett JC Jr, et al. Short-term clinical effects of tolvaptan, an oral vasopressin antagonist, in patients hospitalized for heart failure: the EVEREST Clinical Status Trials. JAMA. 2007;297(12):1332-43

8. Matsue $\mathrm{Y}$, Suzuki M, Torii S, et al. Clinical Effectiveness of Tolvaptan in Patients With Acute Heart Failure and Renal Dysfunction. J Card Fail. 2016;22(6):423-32.

9. Felker GM, Mentz RJ, Cole RT, et al. Efficacy and Safety of Tolvaptan in Patients Hospitalized With Acute Heart Failure. J Am Coll Cardiol. 2017;69(11):1399-1406.

10. Schrier RW, Gross P, Gheorghiade M, et al. Tolvaptan, a selective oral vasopressin V2-receptor antagonist, for hyponatremia. N Engl J Med. 2006;355(20):2099-112.

11. Shanmugam E, Doss CR, George M et al. Effect of tolvaptan on acute heart failure with hyponatremia--a randomized, double blind, controlled clinica trial. Indian Heart J. 2016;68 Suppl 1:S15-21.

12. Udelson JE1, Smith WB, Hendrix GH, et al. Acute hemodynamic effects of conivaptan, a dual $\mathrm{V}(1 \mathrm{~A})$ and $\mathrm{V}(2)$ vasopressin receptor antagonist, in patients with advanced heart failure. Circulation. 2001;104(20):2417-23.

13. Goldsmith SR1, Elkayam U, Haught WH, et al. Efficacy and safety of the vasopressin V1A/V2-receptor antagonist conivaptan in acute decompensated heart failure: a dose-ranging pilot study. J Card Fail. 2008 Oct;14(8):641-7.

14. Vidic A, Shuster JE, Goff ZD, Godishala A, Joseph SM, Chibnall JT, Hauptman PJ. Vasopressin antagonism for decompensated right-sided heart failure. Int J Cardiol. 2018 Aug 13. [Epub ahead of print]

15. Ponikowski P, Voors AA, Anker SD, et al. 2016 ESC Guidelines for the diagnosis and treatment of acute and chronic heart failure: The Task Force for the diagnosis and treatment of acute and chronic heart failure of the European Society of Cardiology (ESC). Developed with the special contribution of the Heart Failure Association (HFA) of the ESC. Eur Heart J. 2016;37(27):2129-2200

16. Shewan LG, Coats AJS, Henein MY Authors' Responsibilities and Ethical Publishing. International Cardiovascular Forum Journal 2018;13:3-4, DOI: 10.17987/icfj.v13i0.525. 